\title{
Use of Flash Simulations to Enhance Nanotechnology Education
}

\section{Dr. Lifang Shih, Excelsior College}

Li-Fang Shih received her Ph.D. in curriculum and instruction with specialization in online instruction from the State University of New York at Albany. Dr. Shih is current the Associate Dean for the School of Business and Technology at Excelsior College. Her researches have focused on issues related to quality online instruction, outcome assessments, online communication, and the development of online community, etc. Her papers have been presented in national conferences such as American Education Research Association (AERA), American Society for Engineering Education (ASEE), WebMedia, and WebNet, etc.

\section{Dr. Jane LeClair, Excelsior College}

Dr. LeClair is currently the Dean of the School of Business and Technology at Excelsior College in Albany, New York. Dr. LeClair, whose career in the nuclear industry has spanned two decades, has worked in various management positions for Constellation Energy. A past Chair of the ANS ETWD division, she received the ANS Training Excellence Award and is the current and past chair of the ANS Conference on Nuclear Training and Education. She is a past ASEE Regional Chair and chaired the ASEE regional conference in 2011. She also is the President of ALC Consulting and has been extensively involved with numerous projects for the IAEA.

\section{Dr. Sohail Anwar, Pennsylvania State University, Altoona Campus}

Sohail Anwar has served as the Editor-in-Chief of the Journal of Engineering Technology. He has also served as the Editor-in-Chief of the International Journal of Engineering Research and Innovation. He is serving as the Series Editor of the Nanotechnology and Energy Series, Taylor and Francis Group/CRC Press.

Sohail edited Nanotechnology for Telecommunications and co-edited Advanced Nanoelectronics published by Taylor and Francis Group/CRC Press. He also edited Handbook of Research on Solar Energy Systems and Technologies published by IGI Global Press in August 2012. He is the Editor-in-Chief of the Encyclopedia of Energy Engineering \&Technology published by Taylor and Francis Group.

Dr. Anwar is a Senior Member of IEEE, and a Member of ASEE. He is currently serving as a Commissioner of the Engineering Technology Accreditation Commission (ETAC) of ABET. 


\title{
Use of Flash Simulations to Enhance Nanotechnology Education
}

\begin{abstract}
The numerous developments in the field of nanotechnology underscore a need for educating the technical workforce in nanoscience and technology. Thus, it is necessary that science and technology graduates should be able to integrate the key concepts of nanotechnology into their knowledge bases.
\end{abstract}

Realizing the need for providing nanotechnology education and training at the undergraduate level to technicians and engineering technologists, Excelsior College has recently developed a Nanotechnology Concentration within its on-line Bachelor of Science in Electrical Engineering Technology Program (BSEET). In this concentration, students are required to complete five online, 3 credit-hour upper division courses.

The first one in the above mentioned list of five nanotechnology courses is titled "Introduction to Nanotechnology" (ELEC 305). The course focuses on the conceptual fundamentals of nanoscience and technology and covers topics such as nanotechnology fundamentals, quantum dots, nanosensors, nanomachines, and the nanotechnology applications in engineering, physics, chemistry, and biology.

The second core course in the above mentioned list of nanotechnology courses is titled "Introduction to Nanofabrication Processes" (ELEC 310). This course provides an introduction to the basic principles and methods of nanofabrication and the associated metrology/characterization methods used in industrial and research applications of nanotechnology.

This manuscript focuses on the use of flash simulations to make instructional enhancements in the content of ELEC 305 and ELEC 310. Both these on-line courses combine virtual reality, graphics, text, and sound.

\section{Introduction}

With the advancement of the Internet, on-line instruction is becoming popular in engineering education [1]. Traditional and non-traditional colleges and universities are now using a variety of instruction tools to deliver on-line instruction to their students. Bb9 (Blackboard 9) is an on-line tool that facilitates the development of web-based educational environments. In the case of Excelsior College, delivery of instruction is achieved primarily through the use of Bb9 distance learning tool. The key features of Blackboard are listed in [2].

The key advantage of offering on-line nanotechnology courses is a virtual classroom that is available anywhere: at school, at work, at home, or even on a trip. In addition to the geographic and temporal independence, the on-line nanotechnology courses offered by Excelsior College are of significant help in enhancing the communication skills of students. The students taking these 
courses are able to communicate both synchronously and asynchronously using web-based electronic mail, chat rooms, and electronic whiteboards.

As mentioned before, the Nanotechnology Concentration comprises five on-line upper level undergraduate courses which include:

- Introduction to Nanotechnology

- Basic Nanofabrication Process

- Nanotechnology Process Equipment

- Introduction to Nanofabrication Manufacturing Technology

- Micro-electro-mechanical systems (MEMS)

\section{Course Content}

At Excelsior College, the on-line instruction in nanotechnology is being phased in gradually. At present, two on-line nanotechnology courses have been developed. The first one, titled "Introduction to Nanotechnology" was developed during Spring 2008. This on-line course was offered to the Excelsior College Engineering Technology students during Fall 2008 semester. The second on-line course titled "Basic Nanofabrication Processes" was developed during summer 2009 and will be offered during Spring 2010. Three additional on-line nanotechnology courses will be developed and offered during the 2010 and 2011.

The BSEET Nanotechnology Concentration core course titled "Introduction to Nanotechnology" is a 3 credit-hour on-line course. The course is offered at the junior level of a 4-year undergraduate degree. The topical coverage for this course consists of:

- Manipulation of Materials at Nanoscale

- Carbon Nanotubes

- Semiconductor Quantum Dots

- Nanoparticles

- Nanoshells

- Nanobiology Applications

- Nanosensors Applications

- Nanomedicines

- Molecular Naomachines

Since this is an on-line course, all the students are required to have access to the following computing resources:

- A reasonably up-to-date personal computer that runs Windows 98 or later.

- Availability to MS-Office, especially Word

- Capability to open and display PDF files

- A working and reliable internet connection with a current Web Browser. 
The second on-line nanotechnology course offered by Excelsior College is titled "Introduction to Nanofabrication Processes” (ELEC 310). This 4 credit-hour course provides an introduction and basic understanding of the fundamental principles of nanofabrication processes used in industrial and research applications of nanotechnology. This course describes the industrial scaling of nanofabrication techniques and showcases examples of specific industrial applications in electronics, photonics, chemistry, biology, medicine, defense, and energy.

\section{Course Enhancements}

In order to enhance the course content and to improve the instructional effectiveness of ELEC 305 and ELEC 310, Excelsior College has recently implemented the use of flash simulations in these on-line courses. Flash simulations are effective educational media. They are:

- Interactive

- Show objects in 3D by rotating them on the screen.

- Dynamic

- Make use of virtual reality.

As described in [3], the use of a web technology, such as Flash, Java, or Java Script, to create an animation of a system moving dynamically, is very helpful in developing a clear understanding of the course concepts. Many students are visual learners and thus animation of a physical system can be an important tool to help them learn.

The flash simulations are used in ELEC 305 and ELEC 310 on-line courses to explain the key concepts of nanoscience and technology. As shown in Figures 1 to 14, the flash simulations illustrate the following concepts:

- Lattices (Figure 1)

- Quantum dots (Figure 2)

- Chirality (Figure 3)

- Medical Applications of Nanotechnology (Figure 4)

- Protein Nanosensors (Figure 5)

- Nanomachines (Figure 6)

- Donor \& Acceptor type doping in a semiconductor crystal lattice (Figure 7)

- Rotation Speed effect on Silicon Ingot Quality(Figure 8)

- Clean Room Contaminants (Figure 9)

- Silicon Wafer Size/Die Size Yield Ratios (Figure 10)

- Silicon Dioxide Growth Parameters (Figure 11)

- Silicon Wafer Lithography (Figure 12)

- Silicon Wafer Lithography (Figure 13)

- Lithography Resolution Process Roadmap (Figure 14) 


\section{Conclusion}

Virtual reality simulations, such as flash simulations make the nanoscale object "visible" to students. The use of these simulations helps students understand the concepts of nanoscale science. It is due to this realization that flash simulations are being used in two core on-line courses included in the course list for the BSEET Nanotechnology Concentration offered by Excelsior College. As shown in the Figures 1-14, these simulations are very helpful in providing a clear understanding of key nanoscience and technology concepts such as quantum dots, chirality, nanosensors, and nanomachines. The two courses described in this manuscript focus on the nanotechnology fundamentals and the nanofabrication processes.

\section{Bibliography}

1. Anwar, S., J. A. Rolle, and A. A. Memon. "Development and Delivery of On-line Upper Division Engineering Technology Courses". Proceedings of the 2005 ASEE Annual Conference.

2. Yaprak, E. and L. Anneberg. “Laboratory-Oriented Distance Learning”. Proceedings of the 2003 ASEE Annual Conference.

3. Bielenberg, A. and E. Cheever. "Web-Based Scripts for Animating System Simulations”. Proceedings of the 2011 ASEE Conference. 


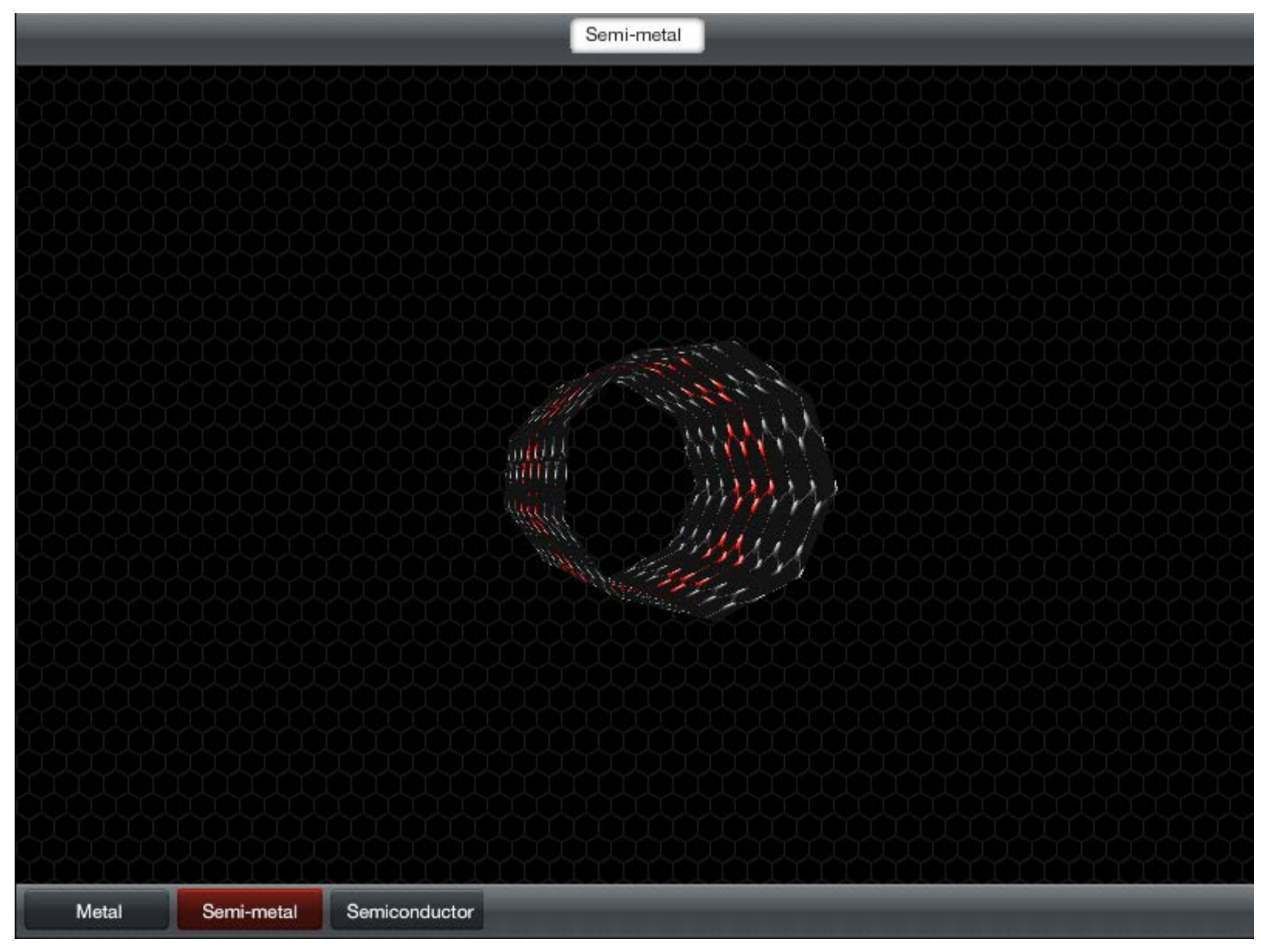

Figure 1: Lattices 


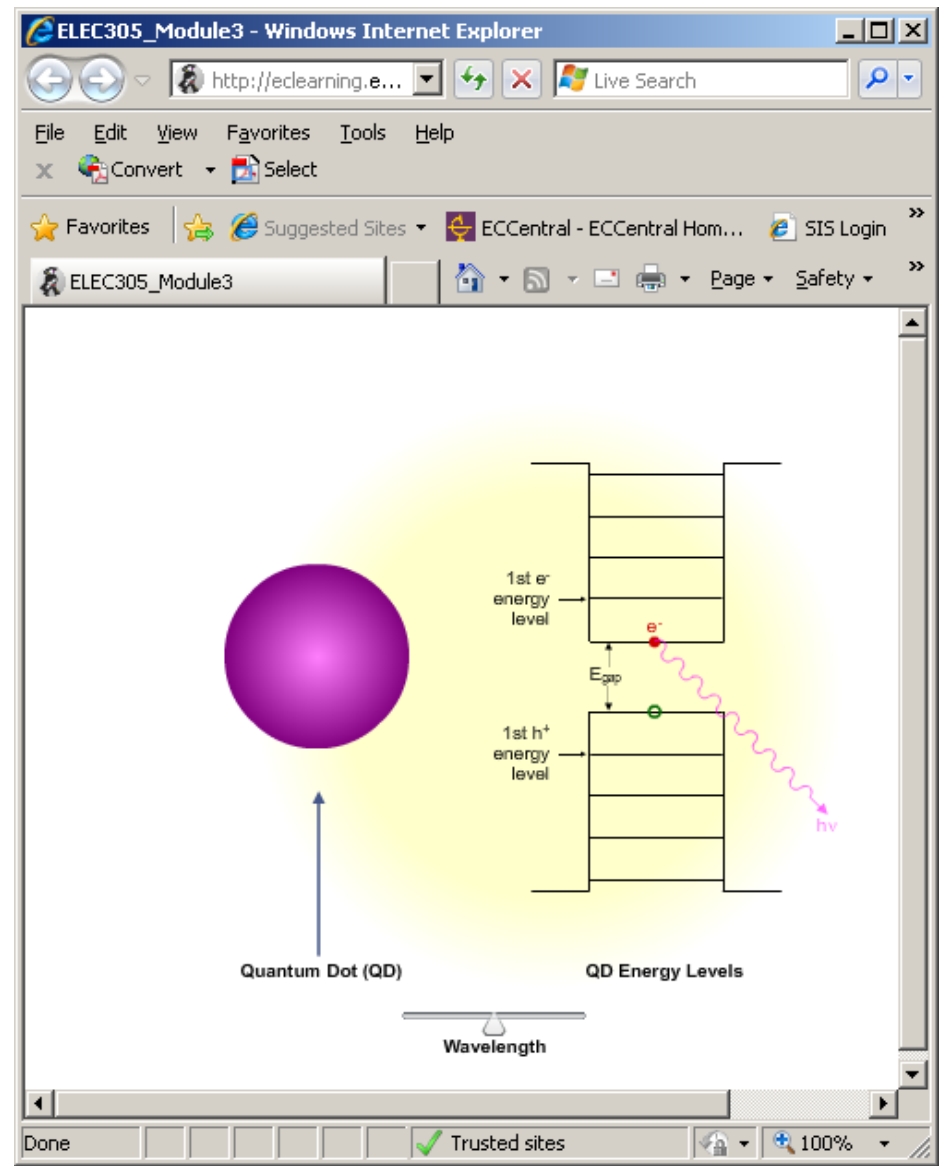

Figure 2: Quantum dots

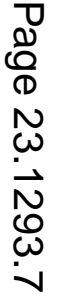



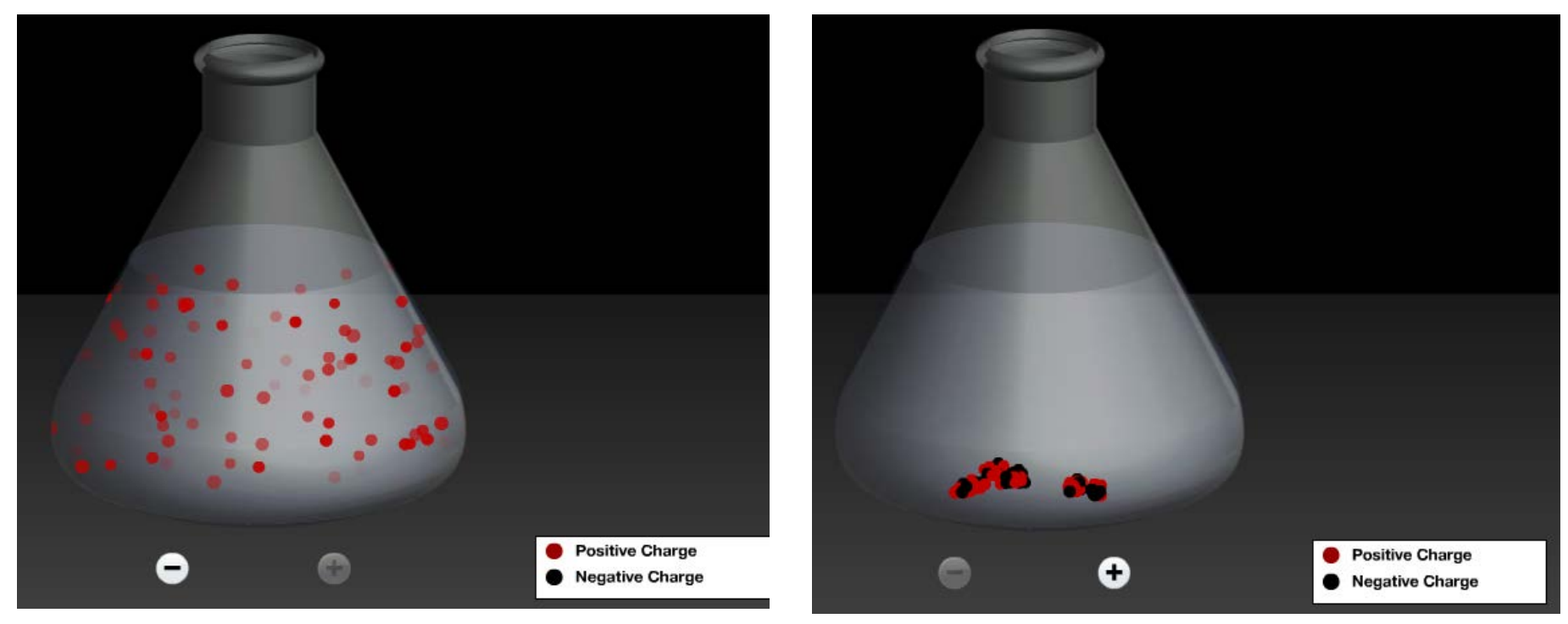

Figure 3: Chirality

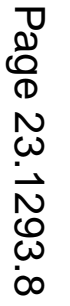


Magnetic Particles are released within the blood stream.

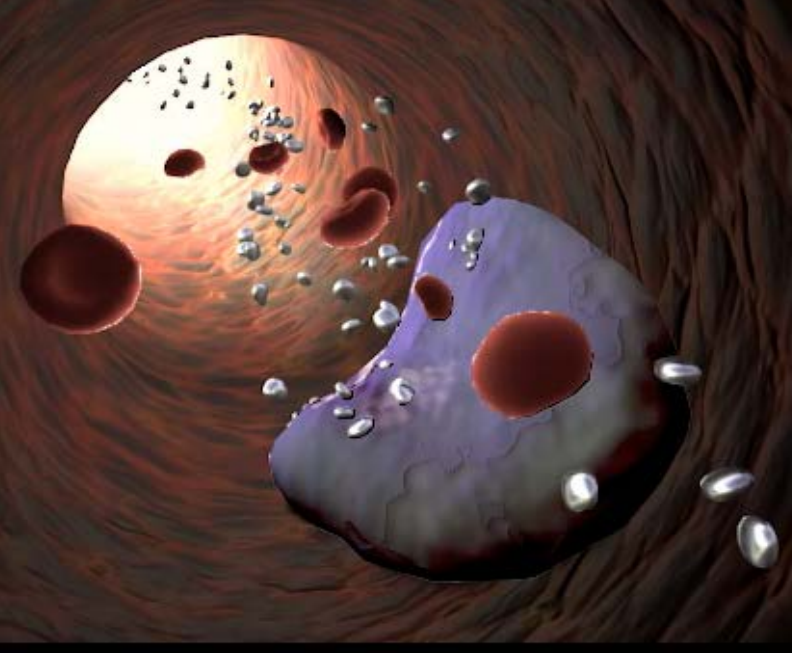

Figure 4: Medical Applications of Nanotechnology 


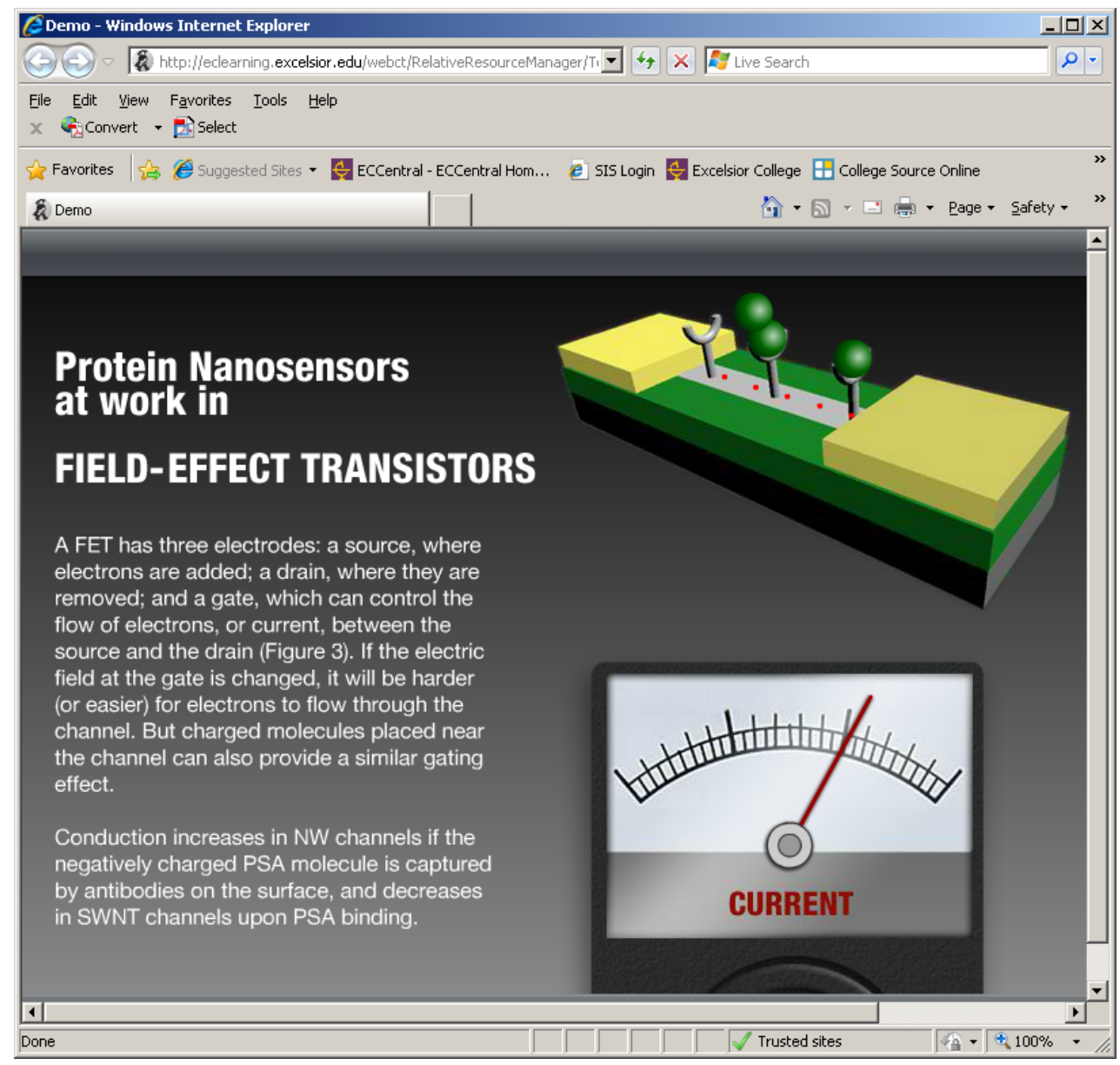

Figure 5: Protein Nanosensors

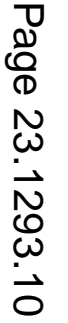




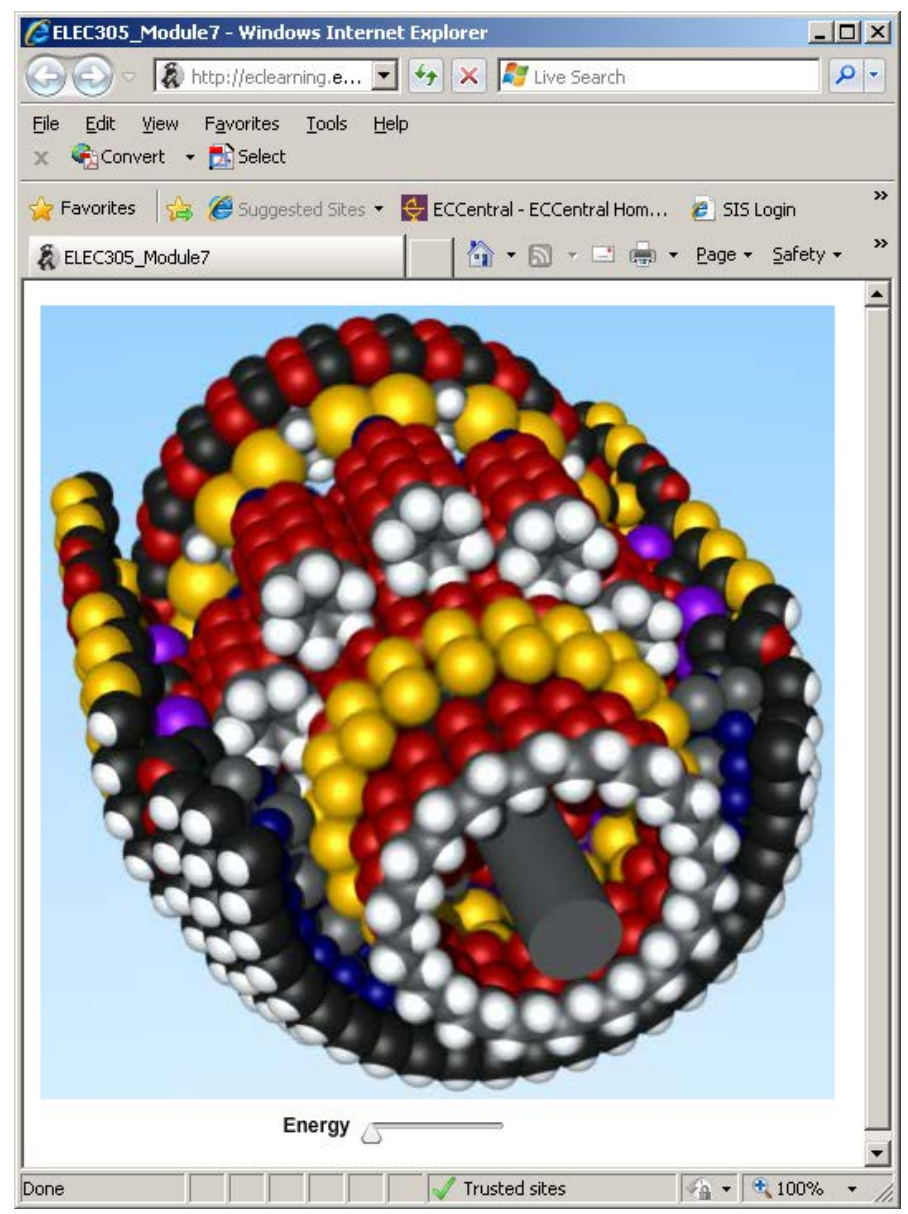

Figure 6: Nanomachines

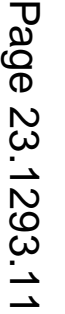




\section{Donor \& Acceptor type doping in a semiconductor crystal lattice}

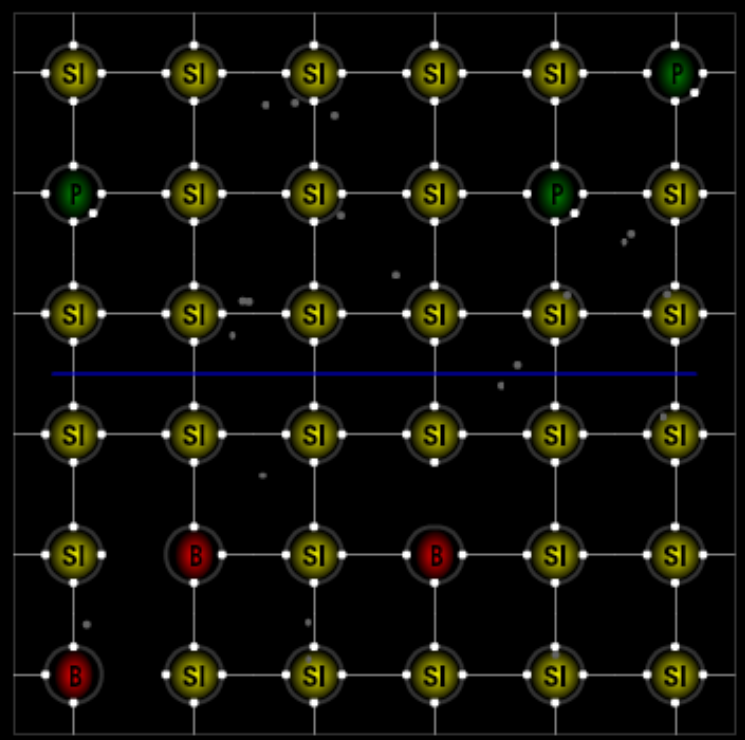

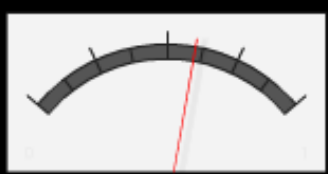

Current

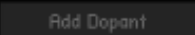

Voltage off

Figure 7: Donor \& Acceptor type doping in a semiconductor crystal lattice 


\section{Rotation Speed effect on Silicon Ingot Quality}
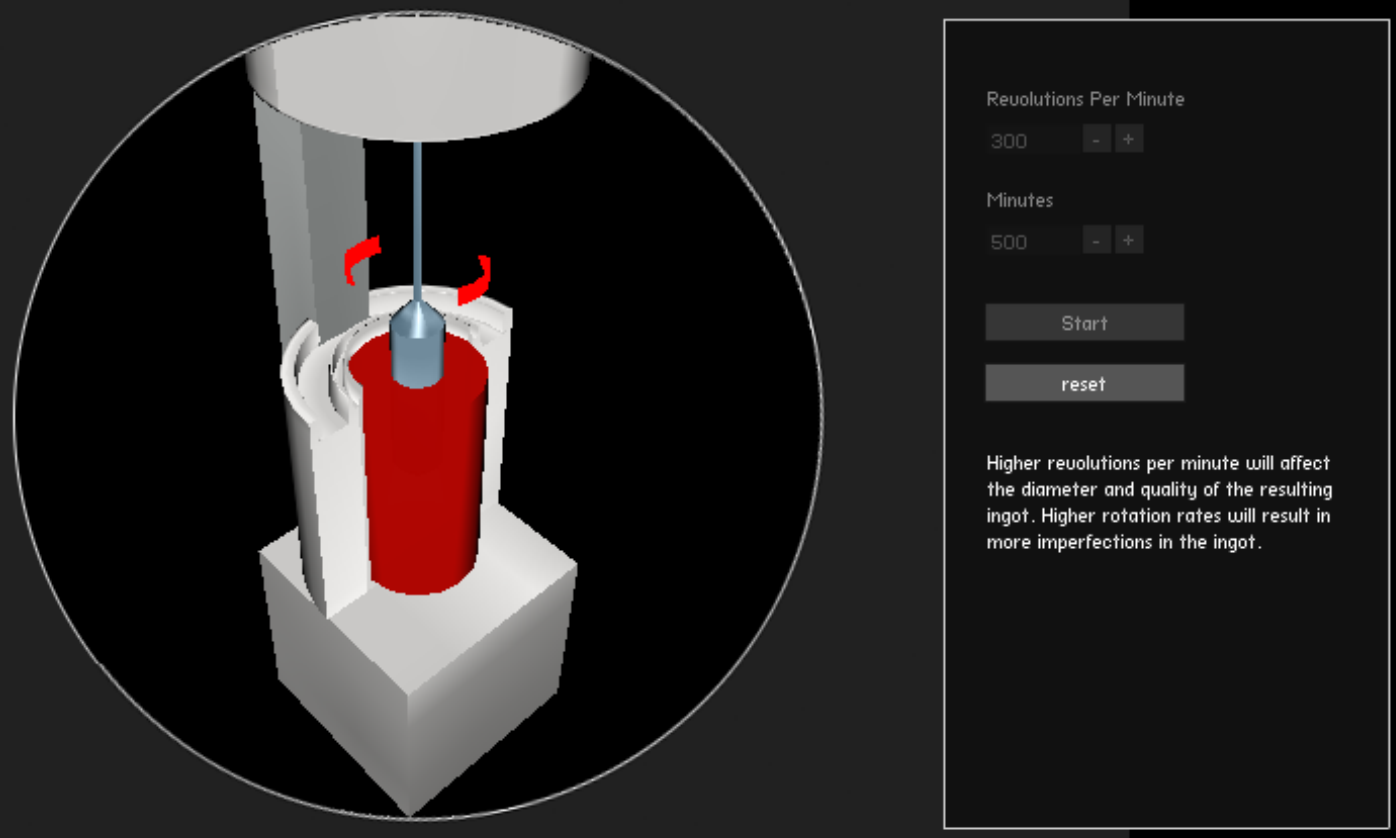

Figure 8: Rotation Speed effect on Silicon Ingot Quality

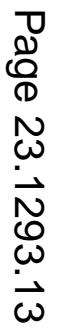




\section{Clean Room Contaminants}

Below are two magnified views through a window into a clean room. The room on the left is a control group showing a well-maintained clean room. The window on the right shows the impact of adding various contaminants to the cleanliness of the room air. Click on the various contaminant types to see what impact they have on air quality.

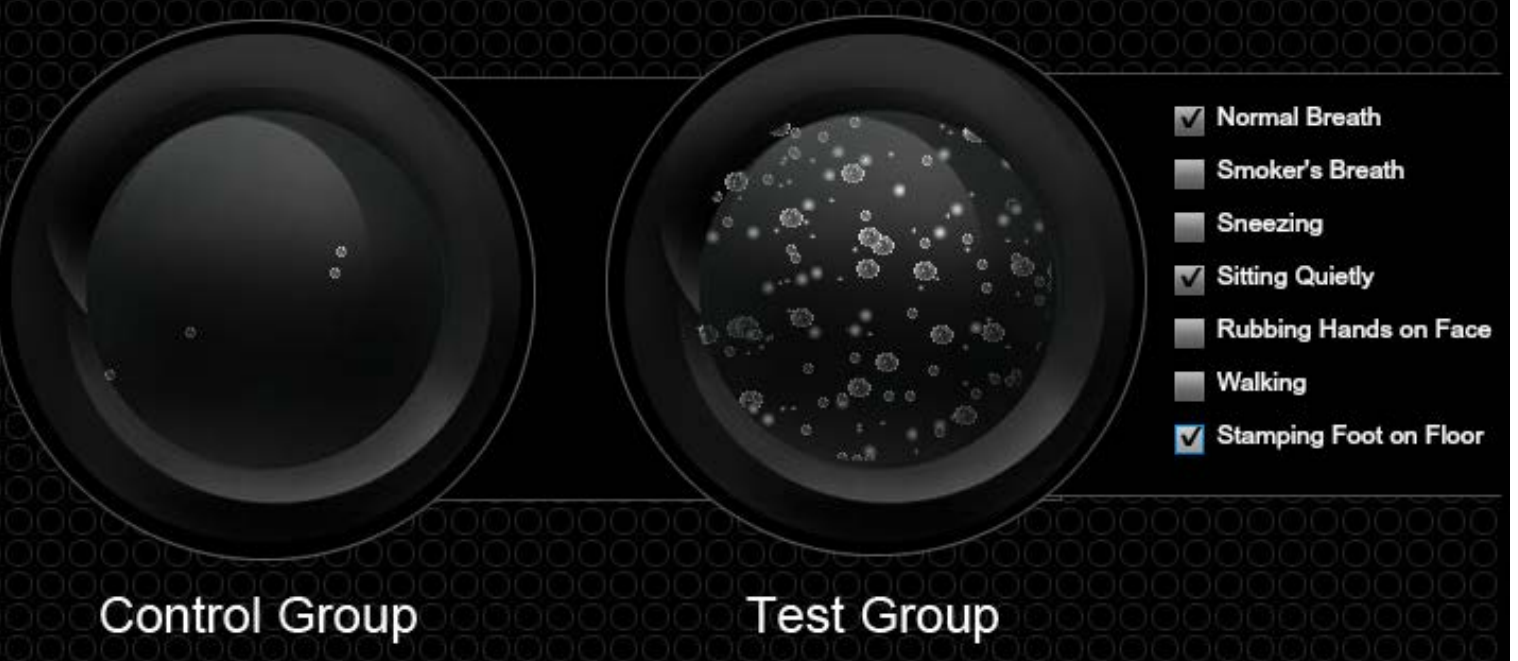

Figure 9: Clean Room Contaminants 


\section{Silicon Wafer Size / Die Size Yield Ratios}

\section{Wafer Size \\ $620-1+$ \\ Die Size \\ $30 \quad-1+$}

Number of Usable Die: 233

Figure 10: Silicon Wafer Size/Die Size Yield Ratios

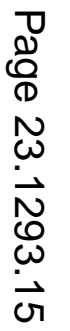




\section{Silicon Dioxide Growth Parameters}
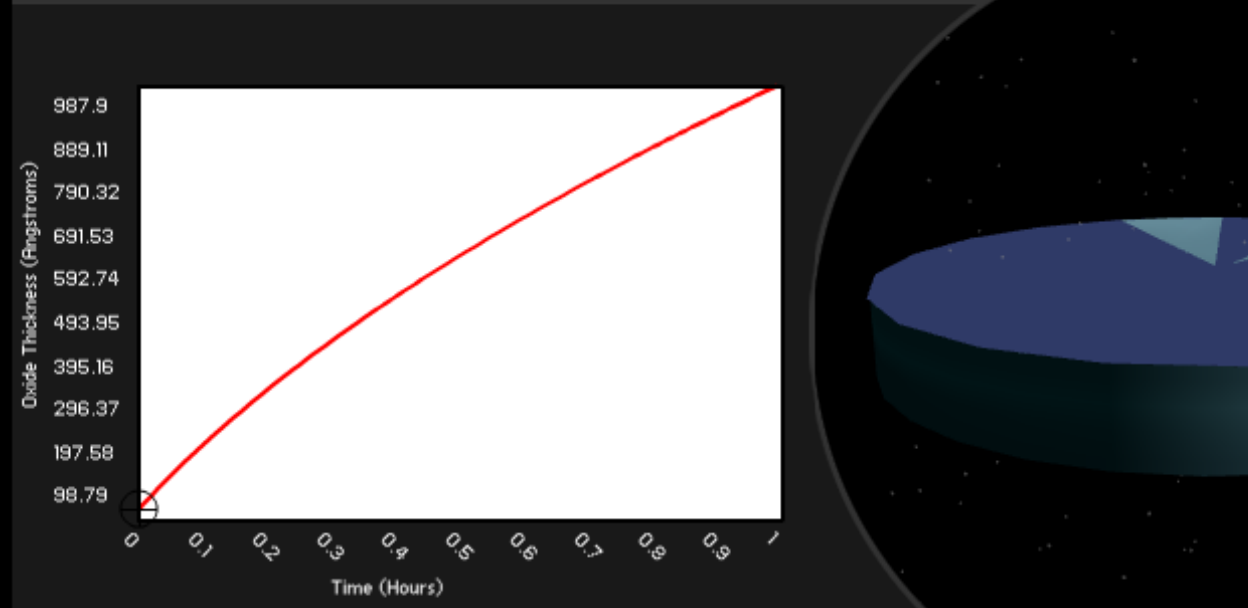

Initial Thickness

25

Temperature $(700-1200 \mathrm{C})$

1100
Oxidation Time ( $30 \mathrm{~m}-4$ hours)

1 Hours 0 Minutes

Enuironment Crystal Orientation

Wet

O 100

no
Colculate

Reset

Figure 11: Silicon Dioxide Growth Parameters

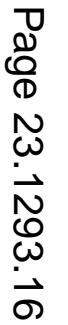




\section{Silicon Wafer Lithography}

\section{Completed Steps}

\section{Drag the steps to their proper order}

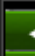

$\checkmark$ Surface Preparation

Photoresist Apply

$\checkmark$ Softbake

+ Hard Bake

I Develop Inspect

* Alignment and exposure

f Development

F Photoresist Removal (strip)

Etch

* Final Inspection

\section{Surface Preparation}

Clean and dry wafer surface.

\section{Photoresist Apply}

Spin coat a thin layer of photoresist on surface.

\section{Drag to Rotate}

\section{Softhake}

Partial evaporation of photoresist solvents by heating.

\section{Softhake}

Partial evaporation of photoresist solvents by heating.

Figure 12: Silicon Wafer Lithography

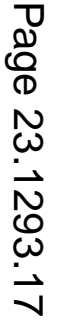




\section{Silicon Wafer Lithography}

Select the correct echant and method by clicking on a test tube.

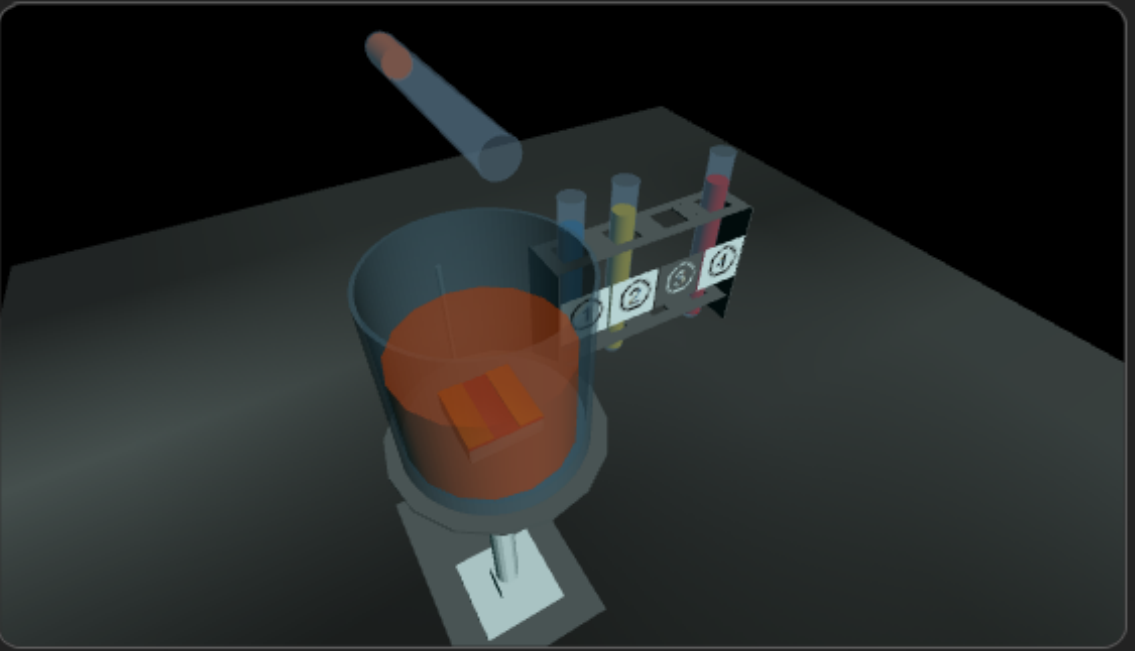

Echant 3 of 4

Echant Composition:

$\mathrm{HNO}_{3}: 50$

$\mathrm{H}_{2} \mathrm{O}: 20$

$\mathrm{HF}: 3$

Method:

Dip

\section{Temperature:}

Room

CURRENT WAFER COMPOSITIONE

SCEIIARIO: 1 OF 4 $\mathrm{SIO2}$

Figure 13: Silicon Wafer Lithography

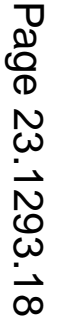




\section{Lithography Resolution Process Roadmap}

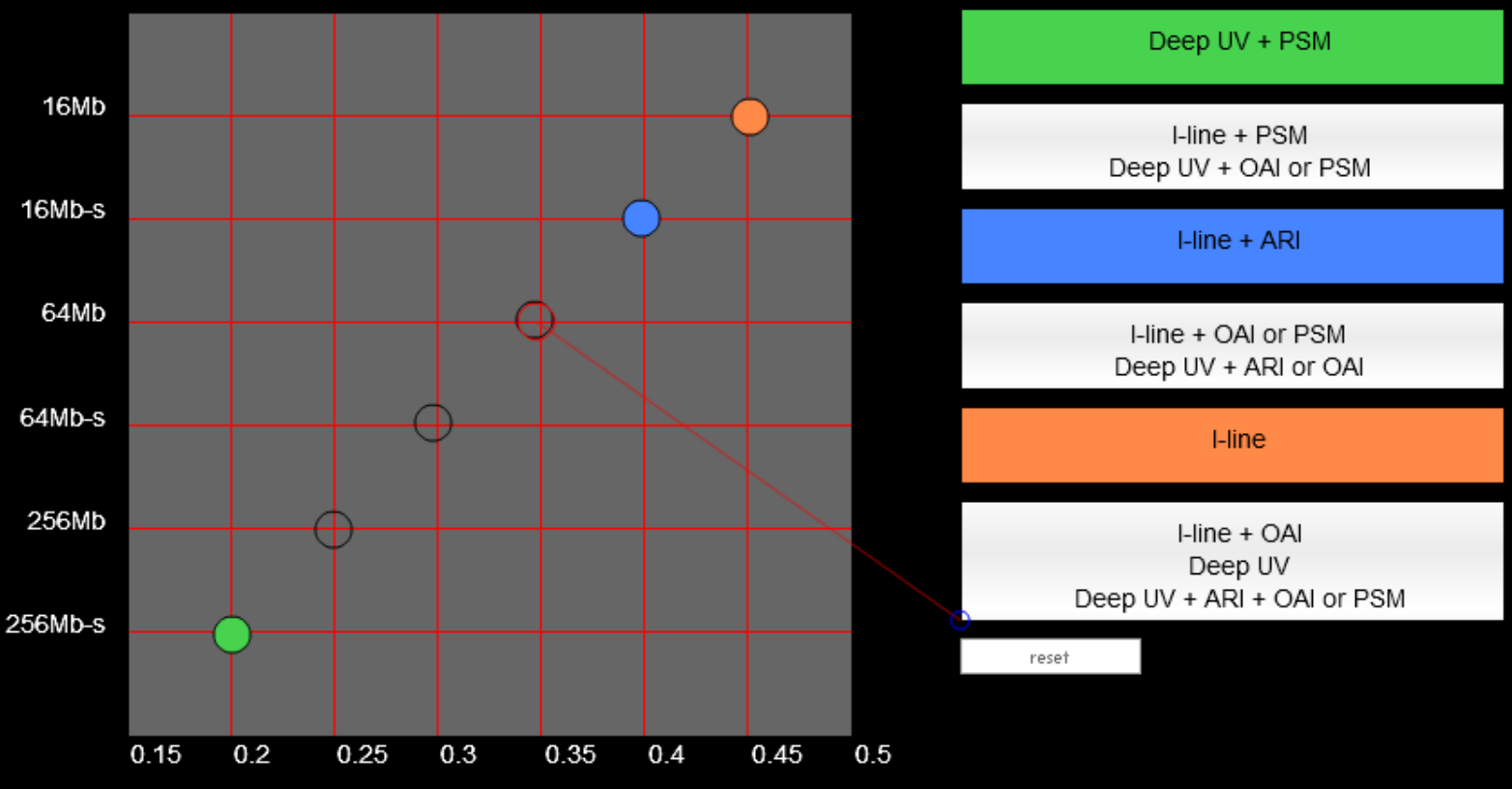

Figure 14: Lithography Resolution Process Roadmap 